\title{
VOIDS AND MICROSTRUCTURE EVOLUTION IN ALUMINIUM SHEETS DURING HIGH DEFORMATION
}

\author{
Florin POPA ${ }^{1, a,{ }^{*}}$, lonel CHICINAŞ ${ }^{1, b}$, Dorel BANABIC ${ }^{1, c}$ \\ ${ }^{1}$ Technical University of Cluj-Napoca, Cluj-Napoca, Romania \\ a florin.popa@stm.utcluj.ro, ${ }^{\mathrm{b}}$ ionel.chicinas@stm.utcluj.ro, ${ }^{\mathrm{c}}$ banabic@tcm.utcluj.ro
}

Keywords: aluminium, deformation, voids, scanning electron microscopy, Feret diameter.

\begin{abstract}
The aim of the study is to identify the microstructure and voids evolution during the aluminium AA6016-T4 sheet deformation up to $93 \%$ in order to perform deformation simulation for future applications. The deformed samples were cut in the rolling direction and to an angle of 45 and respectively 90 degrees to the rolling direction. The low deformed sample exhibit elliptic voids that are flattening out and for high deformed samples a new generation of rounded voids are generated. The microstructure evolution during cold work was studied by scanning electron microscopy and the distortion of the grain is discussed. The grain size evolution and the shape of grains related to the forming degree is analyzed.
\end{abstract}

\section{Introduction}

Aluminium and aluminium alloys are highly deformable and one of the most used materials in automotive industry, with the main purpose of weight reduction and to enhance the performance of some components [1]. For achieving the size reduction the metal sheets must be cold worked up to the desired thickness and during this process voids occurs and stress is induced in the material along with microstructural changes. The forming limit of aluminium alloys employed in auto industry is characterized by the failure initiation due to localized necking, ductile fracture (promoted by void nucleation, void growth and void coalescence) and shear fracture (promoted by shear band localization) [2].

One of the most used aluminium alloy is the AA6016-T4 alloy. This alloy is interesting compared with similar materials because it has the best bending performance. The bending performances can be affected negatively by intermetallic particles naturally presented in such alloys. In addition this alloy present moderate strength, good corrosion resistance and surface quality regarding roping [3]. Other factor is the influence of the microstructure on the mechanical properties of this alloy and on his resistance during service as the final auto part. The texture in aluminium alloys plays an important role in the formability of alloys with implication in the material strength by changing the slip system geometry. It is important to control the texture in sheet processing to achieve optimal performance and quality for applications [4].

Several studies concerning the determination of forming limit curves and planar anisotropy on AA 6016 -T4 were performed. The influence of the pre-deformation on the formability of the material was analyzed, without considering the microstructure evolution during the deformation process [5 - 7]. For aluminium alloys was found that up to a strain of nearly $100 \%$ no damage appears in the necked zone [8]. In order to identify the planar anisotropy the strain distribution is employed in the construction of car hood geometry [9].

The microstructure of hot rolled aluminium consist in very elongated band structure with the possibility of secondary phase precipitation. In the case of cold rolling the sheet center exhibits stronger orientation that the exterior layers. The rolling texture strength influence the final recrystallization texture [10]. 
AA6016 alloys rapid quenched after solution treatment leads to a minor increase of the tensile strength with no effect on the bendability, but decreases significantly the crack growth after bending. In addition the cracks are found to be initiated along the shear bands near intermetallic particles [11]. In punch test the effect of temperature was investigated and it was observed that with increasing temperature the drawing force decrease significantly [12].

The analysis of the void evolution in different direction to rolling direction indicates the void volume increases as the deformation degree increases, with similar behaviour on the 0 and 90 degree direction but with a more rapid evolution on the 45 degree direction [13].

In automotive industry another largely used material is low carbon steel. Our previously work was focused on the voids and microstructure evolution in the high deformed DC04 steel [14]. For the DC04, changes in ferrite microstructure from equiaxial grain to fibrous structure at $89 \%$ cold work was found and, as well was found that the voids are elongated in the rolling direction. Our naturally continuation was tis study to see what happens with aluminium grains and voids as they are subjected to high cold work, having in mind the usage of both alloy in the automotive industry.

\section{Materials and experimental procedure}

Aluminium sheets AA6016-T4 having the composition: $0.25-0.6 \% \mathrm{Mg}, 1.0-1.5 \% \mathrm{Si}, 0.5 \% \mathrm{Fe}$, $0.2 \% \mathrm{Cu}, 0.10 \% \mathrm{Cr}, 0.15 \% \mathrm{Ti}, 0.20 \% \mathrm{Mn}, 0.20 \mathrm{Zn}$ and $\mathrm{Al}$ was subjected to cold work, at room temperature, using a $100 \mathrm{~mm}$ rolling mill. The thickness reduction was in the range 20 to $93 \%$ from the initial thickness. The deformed samples were cut in the rolling direction and to an angle of 45 and respectively 90 degrees to the rolling direction. The samples where cut to these angles in order to correlate the anisotropic properties of the cold rolled samples with the crystallographic texture [15]. The voids evolution after high deformation was studied by scanning electron microscopy (SEM) (Jeol - JSM 5600LV) on the section in the rolling direction. The samples were embedded in resin and polished. For microstructural observation, the polished samples were etched with $\mathrm{NaOH}$ reagent $(20 \% \mathrm{NaOH}$ concentration). The images obtained by SEM were processed in order to enhance the grain boundaries and analyzed with Image $J$ software for the determination of the Feret diameter and circularity of the grains. In order to obtain reliable data, multiple images recorded at the same magnification were analyzed and the mean result is given in this paper.

\section{Results and discussions}

The voids analysis on the sheet surface and in the rolling direction indicates changes in the voids number and shape during the cold work process, as presented in Fig. 1. At $20 \%$ deformation a relatively large number of voids can be observed. The voids evolve at $40 \%$ cold work from spherical/elliptical voids to very elongated voids, aligned in the rolling direction. The aligned voids coalesce during the higher cold works and they are completely disappeared up to $70 \%$ deformation degree. At $70 \%$ cold work the number of voids is smaller than at $20 \%$, but their shape is again almost spherical. The disappearance of the elliptical voids can be related with the plasticity of the aluminium at these cold works. Increasing the cold work up to $90 \%$, the voids previously formed start to growth. They number is not different from that recorded at $70 \%$ cold work.

The evolution of the voids suggests that up to $40 \%$ cold work the voids are deformed and they disappear by flattening out due the induced stress, the number of new formed voids is limited. The disappearance of the voids and reoccurrence as rounded voids for higher cold works indicate a good plasticity of the structure. The re-apparition of the rounded voids could be connected with the activation of a slip system due to the exceeding of the maximum shear stress. For high cold work a similar behaviour has been evidenced for DC04 steel sheets [14]. In aluminium the precipitates (usually known to exist for this alloy) retard the tendency to form dense dislocation walls [16], behaviour that can also lead to void reduction as the cold work value increases. 

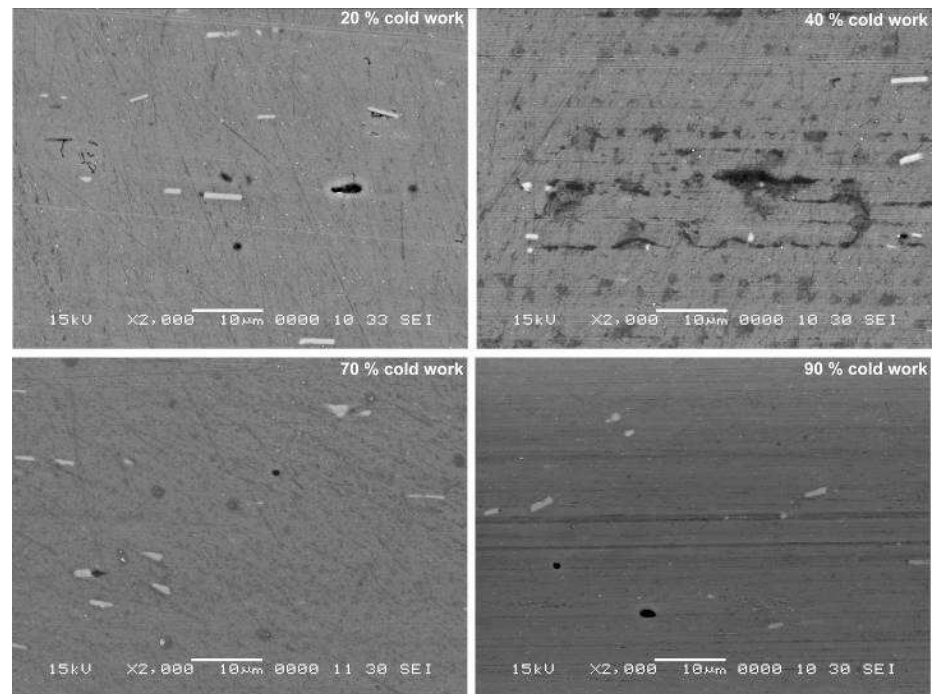

Fig. 1. SEM images of the samples deformed for different degrees. The shape of the voids is analysed in parallel section on the rolling direction.

In the sections cut at $45^{\circ}$ to rolling direction the voids seems to follow a different evolution compared with $0^{\circ}$, as illustrated in Fig. 2.
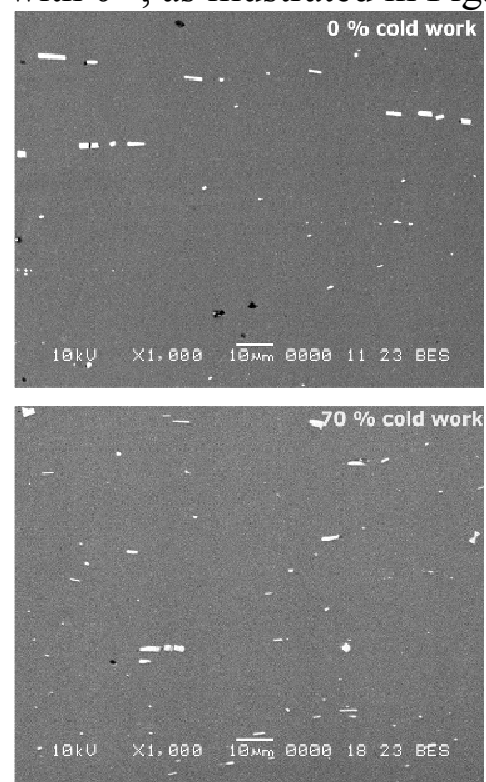
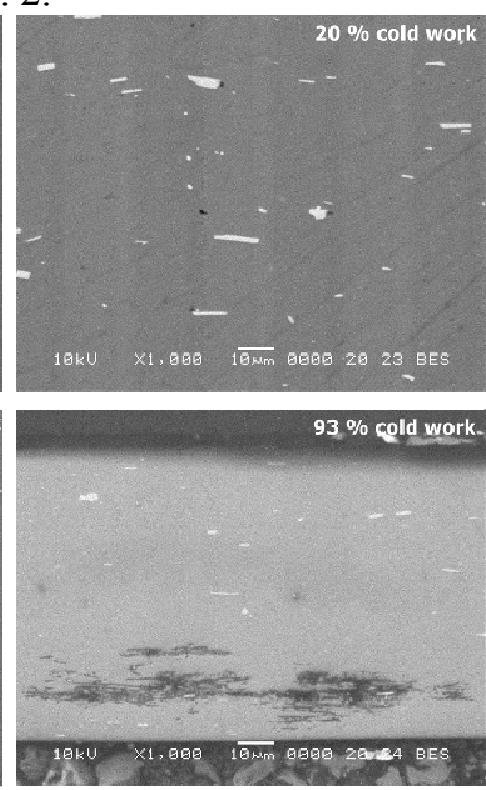
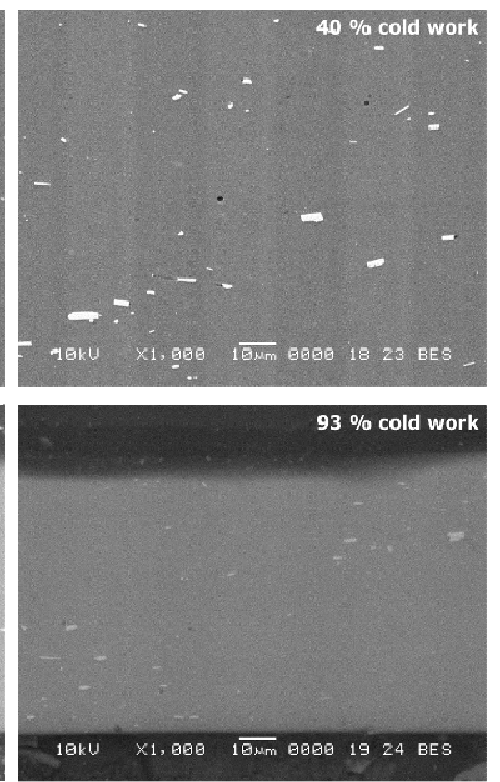

Fig. 2. SEM images of the samples deformed for different degrees. The shape of the voids is analysed in section at $45^{\circ}$ to rolling direction. Magnification 1000x.

At $45^{\circ}$ to rolling direction the shape of voids seems to be unaffected by cold work up to 70 $\%$. In the un-deformed samples are present more voids than in the deformed one. The disappearance of the voids is related with the flattening out induced by cold work. The shape of the void is rounded due to the apparition of the new generated voids in the structure. A particular behaviour is noticed for the highest forming degree $(93 \%)$ where two situation occurs: one the rounded voids and second the complete deterioration of the structure (Fig. 2). The complete deterioration of the structure occurs due to voids coalescence. Such massive deterioration can be the result of the continuous flattening out of the voids at previously forming degrees and finally coalescence of these flattened out to this forming degree.

A second type of analysis was carried out on etched samples in order to observe the microstructural changes during high deformation degree. Concerning the grain size evolution, for the section cut at $0^{\circ}$ to rolling direction, presented in Fig. 3, grain shape and size changes are visible. The un-deformed sample present equiaxial grains with homogeneous size distribution, and 
apparently with no particular orientation. The grain equiaxial structure is maintained at $20 \%$ cold work, but pronounced grain refinement is observed. A relatively poor orientation of the grain in the rolling direction can be observed after $50 \%$ cold work. The elongated grain are the main microstructure of the sample deformed up to $70 \%$. Continuous deformation leads to new grain formation, and the number of the grains increases as the forming degree increases.
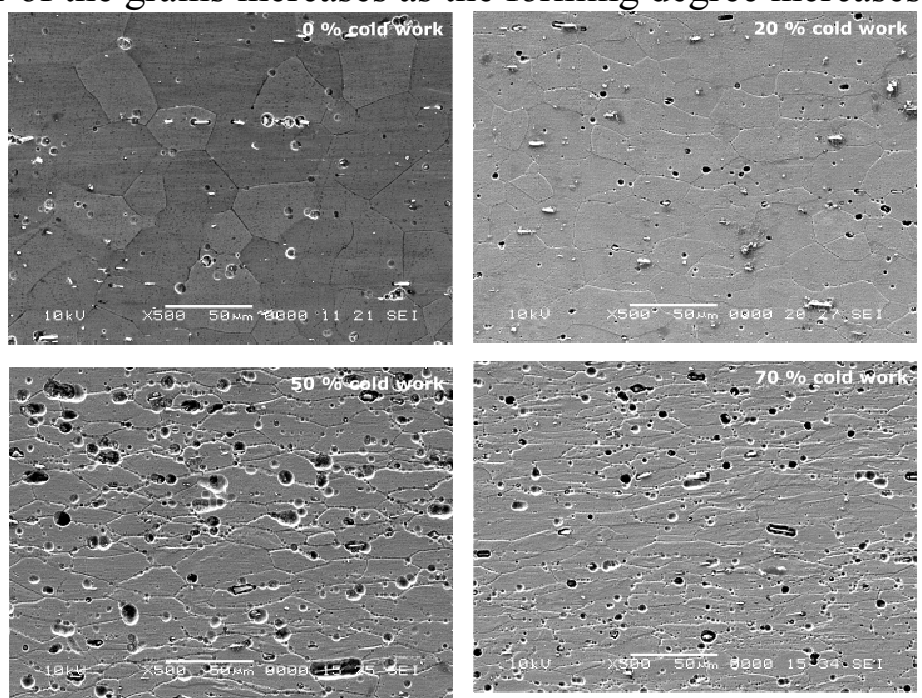

Fig. 3. SEM images of the samples deformed for different degrees and subsequently etched. The microstructure is analysed in section at $0^{\circ}$ to rolling direction. Magnification 500x.

From figure 3, it is also observable that the number of the grains is not changing appreciably, only the shape of the grain become more elongated. Up to $70 \%$ forming degree the fibrous structure is not visible. This behavoiur can be explained by the ageing capability of the material and by composition and void influence on the free development of the grain structure, favoring the grain fracture during deformation [3].
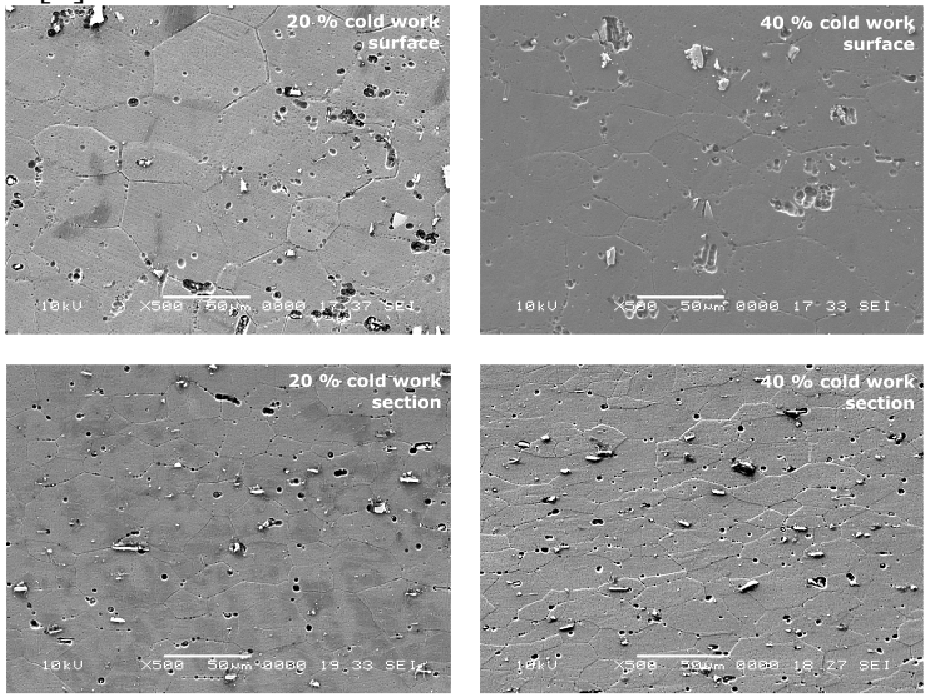

Fig. 4. Comparison of the microstructure of the deformed material on section and surface for the $0^{\circ}$ cut direction. Magnification 500x.

As the samples microstructure evolve in the whole volume of the material the influence of the deformation was studied also in section. In this manner a more 3D image of the influence of the forming degree on the microstructure can be obtained. Fig.4. point out a grain difference between the two zones; the grain sizes on the section are smaller compared with surface. In the $40 \%$ forming degree, in section an orientation of the grain to deformation direction is visible. The surface sample present almost no orientation up to $40 \%$ cold work. 
The observed result concerning the size evolution on surface and section are confirmed by Feret diameter values, as illustrated in Fig. 5.

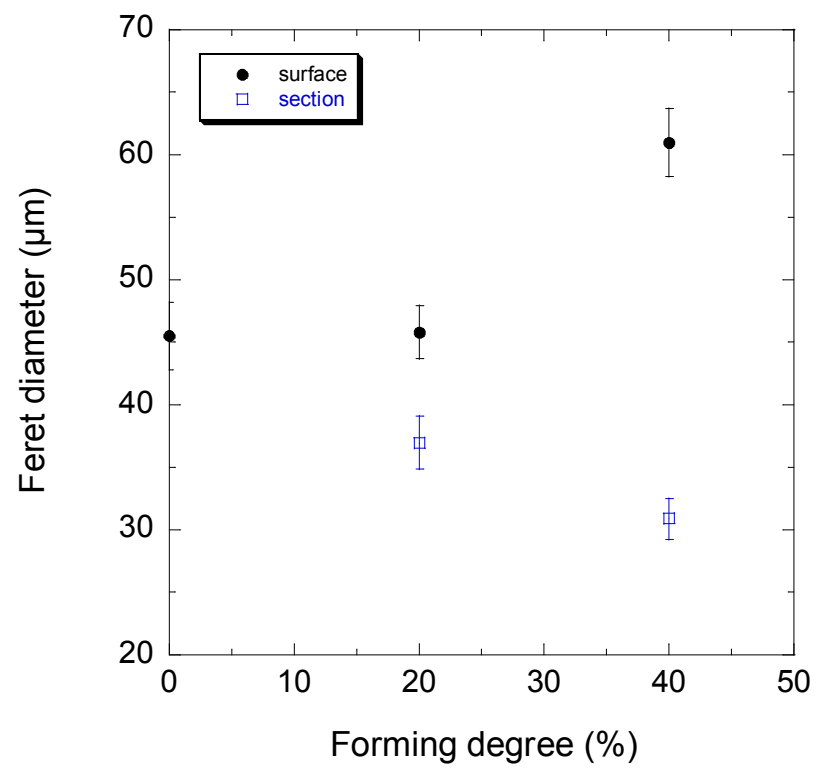

Fig. 5. Evolution of the Feret diameter and of circularity versus the cold work for samples observed on section and on surface. For comparison the Feret diameter of the un-deformed sample is presented.

In order to quantify the size of deformed grains, the Feret diameter is employed. The evolution of the Feret diameter shows an increase (from 45 to $61 \mu \mathrm{m}$ ) of the sizes for the grains observed on surface and a diminution (from 37 to $31 \mu \mathrm{m}$ ) of the grains observed on section. The increase on the surface is the effect of the sample stretch and the reduction on section is the effect of sample compression. A similar increase of the grain size was observed for DC04 steel, but the values for aluminium are higher than form steel.

\section{Summary}

The cold rolling of the AA6016-T4 aluminium sheet leads to important changes concerning the size and shape of the voids. The shape of the voids depends on the deformation degree and changes that occurs in the plasticity of the material. The void evolution can be divided in two stages: up to $40 \%$ cold work a flattening out process take place, followed by a regeneration process, leading again to a new structure with rounded voids that start to grow as the cold work increase in intensity.

The grain structure remains almost unchanged up to $20 \%$ cold work, and start to develop a small orientation at $50 \%$ forming degree, leading to an elongate structure at $70 \%$ cold work. The grain sizes on the section are smaller compared with surface. In the $40 \%$ forming degree, in section an orientation of the grain to deformation direction is visible, but almost no orientation on surface.

The evolution of the Feret diameter shows an increase of the sizes for the grains observed on surface and a diminution of the grains observed on section, bearing witness to stretch on surface and compression on section during cold work.

\section{Acknowledgement}

The authors would like to thank the Romanian Ministry of Education and Research for CNCS Grant, project number PCCE ID100/2010. 


\section{References}

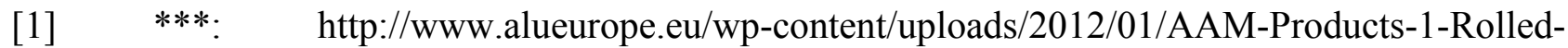
products.pdf, Accessed: 2014-09-08

[2] C. Leppin, D. Daniel, R. Shahani, H. Gese, H. Dell, Formability Prediction Of Aluminum Sheet In Automotive Applications, AIP Conference Proceedings, 908 (2007) 117-122

[3] R. Prillhofer, G. Rank, J. Berneder, H. Antrekowitsch, P. J. Uggowitzer, S. Pogatscher Property criteria for automotive Al-Mg-Si sheet alloys, Mater. 7 (2014) 5047-5068

[4] J. Hirsch, T. Al-Samman, Superior light metals by texture engineering: Optimized aluminum and magnesium alloys for automotive applications, Acta Mater. 61 (2013) 818-843

[5] A. Ofenheimer, B. Buchmayr, R. Kolleck, M. Merklein, Forming limits in sheet metal forming for non-proportional loading conditions - experimental and theoretical approach, Numisheet 2005, Volume A, edited by L. M. Smith, F. Pourboghrat, J. W. Yoon, T. B. Stoughton, American Institute of Physics (2005) 460-465

[6] A. Lamik, H. Leitner, W. Eichlseder, F. A. Riemelmoser, Study of the fatigue behaviour of an aluminium-clad steel material compound, Strain 44 (2008) 440-445

[7] M. C. Butuc, J.J. Gracio, A. Barata da Rocha, An experimental and theoretical analysis on the application of stress-based forming limit criterion, Int. J Mech. Sci. 48 (2006) 414-429

[8] N. Tardif, S. Kyriakides, Determination of anisotropy and material hardening for aluminum sheet metal, Int. J Solids Struct. 49 (2012) 3496-3506

[9] A. Güner, C. Soyarslan, A. Brosius, A. E. Tekkaya, Characterization of anisotropy of sheet metals employing inhomogeneous strain fields for Yld2000-2D yield function, Int. J Solids Struct. 49 (2012) 3517-3527

[10] O. Engler, J. Hirsch, Texture control by thermomechanical processing of AA6xxx Al-Mg-Si sheet alloys for automotive applications-a review, Mater. Sci. Eng. A 336 (2002) 249-262

[11] P. Castany, F. Diologent, A. Rossoll, J. F. Despois, C. Bezençon, A. Mortensen, Influence of quench rate and microstructure on bendability of AA6016 aluminium alloys, Mater. Sci. Eng. A 559 (2013) 558-565

[12] S. Kurukuri, A. H. van den Boogaard, M. Ghosh, A. Miroux, Thermo-mechanical forming of Al-Mg-Si alloys: modeling and experiments, Proceedings of the 10th International Conferecne NUMIFORM 2010, edited by F. Barlat, Y. H. Moon, M.G. Lee, American Institute of Physics, 2010

[13] S. Thuillier, E. Maire, M. T. Brunet, Ductile damage in aluminium alloy thin sheets: Correlation between micro-tomography observations and mechanical modeling, Mater. Sci. Eng. A 558 (2012) 217-225

[14] F. Popa, I. Chicinaș, D. Frunză, I. Nicodim, D. Banabic, Influence of high deformation on the microstructure of low-carbon steel, Int. Min. Metall. Mater. 21 (2014) 273-278

[15] O. Engler, Y. An, Correlation of texture and plastic anisotropy in the Al-Mg alloy AA 5005, Solid State Phenom. 105 (2005) 277 - 284

[16] T. Clausmeyer, T. van den Boogaard, M. Noman, G. Gershteyn, M. Schaper, B. Svendsen, S. Bargmann, Phenomenological modeling of anisotropy induced by evolution of the dislocation structure on the macroscopic and microscopic scale, Int. J Mater. Form 4 (2011) 141-154 